\title{
The vestibular hypothesis of the moon illusion
}

RUSSELL J. WOOD 1 PETER W. ZINKUS, AND PAUL T. MOUNTJOY, DEPARTMENT OF PSYCHOLOGY, WESTERN MICHIGAN UNIVERSITY, Kalamazoo, Michigan

Two experiments were conducted to test the hypothesis that a change in vestibular stimulation can result in apparent discrepancies in the perceived size and distance of two targets of equal size placed at identical distances, but in different planes of space. This effect could be offered as a reasonable explanation, at least in part, for the moon illusion phenomenon.

A recent paper (Thor \& Wood, 1966) offered a new hypothesis to account for the moon illusion: "the moon or any other object varies in perceived size and distance as a direct result of the location of the head and eyes in space, relative to the direction of the force of gravity."

Much of the previous research on the moon illusion has offered tenable, although divergent, hypotheses to account for the gross discrepancies in the apparent size of identical objects viewed in both the horizontal and vertical planes. One factor, however, that of changed head position relative to the direction of the force of gravity, seems to have been consistently overlooked, in this frame of reference, until the recent Thor and Wood study. Whether attributing these discrepancies to the position of the eyes in the head (Holway \& Boring, 1940) or to factors of terrain (Kaufman \& Rock, 1962), the obvious variable of head position may be profitable to explore since it is common to all these studies no matter what other variables are controlled for. It is also felt that this phenomenon can be more profitably studied by eliminating extraneous visual cues which may not be controlled in the previously mentioned studies. For this reason, the present study was conducted in a totally darkened room.

Recent discoveries of neuronal integration and coordination between afferent fibers of the vestibular system and the optic cortex (Jung, 1961) suggests a mechanism whereby altered vestibular polarization interacts significantly with visual input. Jung reviews the work of Grusser, Chornels, and Saur which demonstrated that neurons of the visual cortex respond to labyrinthine (vestibular) stimulation. When viewing an object which is in any other plane of space, except that of a right angle to the vertical, the only sensory system that is significantly altered, and capable of responding to such a change, is the vestibular system. This fact, in conjunction with the knowledge that the optic cortex receives sensory input from the vestibular system, is the assumptive basis of this study.

Method and Procedure. The first experiment was designed to test S's ability to match a standard disc, in the vertical plane, with a series of various sized discs presented on the horizontal plane. Each $\mathrm{S}$ was blindfolded and seated in a totally darkened room with a large Masonite board $72 \mathrm{in.} \mathrm{in} \mathrm{front} \mathrm{of} \mathrm{him.} \mathrm{This}$ board contained an aperture through which illuminated red discs, ranging from $2.75 \mathrm{in}$. to $5.00 \mathrm{in}$. in diameter could be present in 0.25 in. gradations. A standard illuminated target was placed directly above the chair and could be raised or lowered so that its distance from $S$ 's eyes was equal to the distance between his eyes and the horizontal disc. After adapting to the room, each $S$ was asked to tell the $\mathrm{E}$ when the standard disc, in the vertical plane, and one of the various discs in the horizontal plane were equal in size. Each $\mathrm{S}$ was allowed to change his line of vision from horizontal to vertical as frequently as desired in order to compare discs, and upon his request, the next in the series was presented. The $\mathbf{S}$ was also allowed to return to a previous disc, if he so desired, in order to make a precise judgment. A total of 30 Ss were given one trial apiece in this manner, except that $10 \mathrm{Ss}$ had a standard target of $3.50 \mathrm{in}$., $10 \mathrm{Ss}$ matched a $3.75 \mathrm{in}$. standard, and the remaining $10 \mathrm{had}$ a standard of $4.50 \mathrm{in}$. Results are summarized in Table 1.

In the second experiment, involving $33 \mathrm{Ss}$, an illuminated white disc was placed 59.00 in. in front of S's chair. A disc of equal size and illumination was suspended vertically, by means of a rope and pully, directly above the $S$ 's chair. Again seated in a totally darkened room, each $S$ was instructed to hold the rope, and by manipulating it, place the vertical target the same distance away from him as the horizontal disc. The starting position (distance) of the vertical disc was alternated for every $S$, first above 59.00 in. then below 59.00 in. Each $S$ received one trial. Results of lixperiment 2 are also sunmarized in Table 1.
Table 1

Mean Size and Distance Judgments for Horizontal and Vertical Positions (Distance estimates in inches and size estimated in inches of diameter.)

Experiment $1(\mathrm{~N}=30)$

\begin{tabular}{cc}
$\begin{array}{c}\text { Size of Standard } \\
\text { (Vertical) }\end{array}$ & $\begin{array}{c}\text { Mean Judgment } \\
\text { (Horizontal) }\end{array}$ \\
\hline 3.50 & 3.10 \\
3.75 & 3.20 \\
4.50 & 4.00 \\
\hline
\end{tabular}

Experiment $2(\mathrm{~N}=33)$

\begin{tabular}{cc}
$\begin{array}{c}\text { Distance of Standard } \\
\text { (Horizontal) }\end{array}$ & $\begin{array}{c}\text { Mean Judgment } \\
\text { (Vertical) }\end{array}$ \\
\hline 59.00 & 42.70 \\
\hline
\end{tabular}

Results and Discussion. As shown in Table 1, S's responses in both experiments indicate the discs of equal size are not perceived as such when viewed in different planes of space. In Experiment 1, only eight of 30 Ss successfully matched the targets, while only one selected a larger disc on the horizontal plane. The majority of Ss chose a smaller disc on the horizontal plane as being equal to the larger vertical standard. In Experiment 2, all 33 Ss indicated a distance discrepancy by placing the overhead target closer to themselves than the standard, thus indicating that they perceived the horizontal disc as larger.

In these studies, vestibular stimulation was accomplished by tilting the head and eyes when looking upward at the overhead targets. In spite of the fact that vestibular stimulation is difficult to isolate, there seems to be a paucity of tenable explanations for the size-distance discrepancies found in this study. The hypothesis is further strengthened by the fact that the study was conducted in a totally darkened room, void of extrinsic cues.

The data obtained are consistent with those reported by Thor and Wood. They demonstrated that when Ss viewed overhead targets, they were judged to be smaller and farther away than targets of equal size and distance in the horizontal plane. horizontal plane.

The significant results of this experiment seem to be: the moon illusion can, at least in part, be attributed to changes in vestibular stimulation. Effects of terrain, the flattened sky effect, and other explanations which attribute the cause entirely to factors outside of the organism, seem to have less credibility in explaining the results of this study since a change in head and eye position, causing a corresponding alteration of vestibular impulses to the optic cortex, apparently was the only variable manipulated.

Since it is impractical to sub-cortically implant area 17 of the optic cortex of human Ss and record changes in nerve potentials during the experiment, the vestibular hypothesis itself is only tenable and subject to modification. However, considered in the light of recent discoveries that certain neurons of the visual cortex do indeed respond to labrynthine stimulation, the results of this experiment, as interpreted by the vestibular hypothesis, become more meaningful.

\section{REFERENCES}

THOR, D. H., \& WOOD, R. J. Paper presented at Midwest Psychological Association, Chicago, May, 1968.

HOLWAY, A. H., \& BORING, E. G. The moon illusion and the angle of regard. Amer. J. Psychol., 1940, 53, 109-116.

KAUFMAN, I., \& ROCK, I. The moon illusion. Scient. American, 1962, 135 , 1125-1126.

JUNG, R. Neuronal integration in the visual cortex and its significance for visual information. In Rosenblith (Ed.), Sensory communication. New York and London: Wiley and Sons, 1961. Pp. 627-674.

\section{NOTE}

1. Now at Nathaniel Hawthorne College, Antrim, New Hampshire. 